Research Article

\title{
Analyzing Design Considerations for Disassembly of Spent Nuclear Fuel during Head-End Process of Pyroprocessing
}

\author{
Young-Hwan Kim (iD) and Yung-Zun Cho \\ Korea Atomic Energy Research Institute, Daedeok-daero 989-111, Yuseong-gu, Daejeon 305-353, Republic of Korea \\ Correspondence should be addressed to Young-Hwan Kim; yhkim3@kaeri.re.kr
}

Received 2 May 2020; Accepted 14 October 2020; Published 26 October 2020

Academic Editor: Peter Ivanov

Copyright () 2020 Young-Hwan Kim and Yung-Zun Cho. This is an open access article distributed under the Creative Commons Attribution License, which permits unrestricted use, distribution, and reproduction in any medium, provided the original work is properly cited.

\begin{abstract}
We have developed a practical-scale dry disassembling process to dismantle PWR (Pressurized Water Reactor) spent nuclear fuel assembly in the order of several tens of kilograms of heavy metal/batch to supply rod-cuts (cladding tube and $\mathrm{UO}_{2}$ pellets) for mechanical decladding process. Dry head-end disassembling process has advantages over the wet head-end process because of the lower risk of proliferation and treatment of spent fuel with relatively high heat and radioactivity. This study describes the main design considerations for the disassembling process of the spent nuclear fuel assembly during the dry head-end process. The down-ender, dismantling, extraction, and cutting technologies are analyzed and models have been designed for testing. The purpose of dry head-end disassembly process is to test the main device performance and to obtain scale-up data for practical-scale disassembling. With this in mind, design considerations were analyzed based on remoteness, and basic verification tests were performed. However, the authors used simulated fuel, instead of the actual spent fuel, owing to a lack of joint determination. In addition, in the present study, we did not consider the heat generated from minor actinides or the radioactivity of the fission product; these aspects will be considered in a future study. During the basic test performed in this study, a simulated assembly was completely disassembled using new methods, such as dismantling, extraction, and cutting processes. The practical-scale dry disassembling technology can be tested using scale-up data for reuse of the spent fuel.
\end{abstract}

\section{Introduction}

Spent fuel, which is an essential by-product of electricity generation by nuclear power reactors, is highly radioactive. However, it could be a valuable asset if it is effectively recycled. With the increase in the cumulative amount of spent fuel in Korea, the development of methods for reliable and effective management of this spent fuel has become an important KAERI (Korea Atomic Energy Research Institute) mission. With such a background, KAERI is developing a dry head-end process for pyroprocessing $[1,2]$. Dry processes, including disassembly, mechanical decladding, voloxidation, blending, compaction, reduction, and sintering, shall be performed in advance as the head-end process of pyroprocessing [3]. In addition, for mechanical decladding of the spent fuel in the head-end process, a disassembly process is necessary [4]. The disassembly process includes apparatus for down-ender, dismantling of the spent fuel assembly, rod extraction, and cutting of extracted spent fuel rods.

Head-end technology for recycling nuclear spent fuel is developed and commercialized as a wet process, but this cannot be directly applied to pyroprocessing because of the working environment and conditions. Additionally, the disassembling technology in dry head-end process is in the development stage at a laboratory scale and high throughput technology for commercialization is still in the basic research phase. A hybrid head-end process for processing of the light water reactor (LWR) spent fuel is being developed at the Oak Ridge National Laboratory (ORNL). However, this scheme includes a pyrochemical head-end followed by aqueous separations [5]. Conceptual designs for pyroreprocessing facilities for spent LWR mixed oxide fuel (MOX) fuel have been established, their economic 
competitiveness have been evaluated, and the corresponding disassembling process involves the use of devices, such as the disassembler and chopper in the dry head-end cell with air in Japan [6]. Moreover, JAEA (Japan Atomic Energy Agency) has been interested in conducting a feasibility study of commercialized fast reactor cycle systems. JAEA has also proposed a new disassembly technology using a system that consists of a mechanical cutting step and extraction [7]. Compared to wet processes, extant studies concerning dry head-end processes have been limited to the laboratory scale. However, recent times have witnessed an increasing interest in the use of scale-up equipment in economical pyroreprocessing [6]. This paper presents development and optimization processes for disassembly of spent nuclear fuels through a systematic approach involving analysis, design, and testing. The authors have designed and implemented the proposed high-capacity disassembling apparatus in dry head-end processes. Additionally, the authors have analyzed problems associated with good cross section cutting without deformation and modularization, both of which are not encountered in wet head-end processes, as well as the dry head-end process using low-capacity disassembling apparatus. To enhance the remoteness and the operability for maintenance of the dry head-end process, modularization of the devices was performed using SolidWorks (Version 14). The modular design of the devices for remote operation and maintenance was verified for the disassembly and assembly of the unit assemblies using SolidWorks. Further, analyses such as structural stress and impact load analyses of the devices were conducted based on the structural analysis obtained using SolidWorks. We have also devised some mechanisms to improve the disassembling capacity and conducted tests for verification. In the future, in order to develop a practical-scale dry disassembling process, connectivity and remoteness between unit processes have to be investigated.

\section{Dry Head-End Process}

Figure 1 shows a flow chart of the dry head-end process. The head-end process technology which is one of the key pyroprocessing technologies for treating oxide spent fuels has been making considerable progress since it was proposed in the late 1990 s by KAERI. The main objectives of the pyroprocessing are to reduce the heat load, radioactivity, and volume of processed spent fuels by removing the heatgenerating elements and transforming the oxide fuels into metal fuels for disposal and/or recycling [8]. As shown in Figure 1, the dry head-end process consists of seven major individual processes, namely, disassembling, mechanical decladding, vol-oxidation, blending, compaction, reduction, and sintering [3]. The mechanical decladder is to a decladding apparatus for separating and recovering fuel material and cladding tube by horizontally slitting the cladding tube of a fuel rod and a defective irradiated fuel rod. After mechanical decladding, $\mathrm{UO}_{2}$ fragments are transferred to vol-oxidation process. In the vol-oxidation process, the pellet type-SFs are pulverized by an oxidation under an airblowing condition, and some volatile fission products are removed from the produced powders by using an air flow [9]. After blending, the $\mathrm{U}_{3} \mathrm{O}_{8}$ powder is moved to a compaction process to obtain $\mathrm{U}_{3} \mathrm{O}_{8}$ pellets. Using the produced $\mathrm{U}_{3} \mathrm{O}_{8}$ powders, the porous $\mathrm{UO}_{2}$ pellets were fabricated by the sequential process of lubricant blending, pelletizing, dewaxing, reduction, and sintering [10].

As summarized in Table 1, the advantages and disadvantages of the dismantling technology pertaining to the head-end processing employed by major countries were compared. Currently, in France, wet processes are implemented commercially; however, in Korea, Japan, and the USA, dry processes are still being implemented in laboratories. The table also indicates that most countries' technologies can not only dismantle spent nuclear fuel assemblies in large quantities but also lead to shearing section deformation and fuel damage. However, considering the subsequent process of mechanical decladding, a suitable cutting section technology is required, such as KAERI. In the future, mass processing technology research should be conducted for dismantling the assembly by cutting technology.

As shown in Figure 2, the disassembling process has four-unit apparatus, which comprises of a down-ender that brings the assembly from a vertical position to a horizontal position, a disassembler to remove the upper and bottom nozzles of the spent fuel assembly, an extractor to extract the spent fuel rods from the assembly, and a cutter to cut the extracted spent fuel rods as a final step to transfer the rodcuts (cladding tube and pellets) to the mechanical decladding process.

\section{Experimental Methods}

As shown in Figure 3, we have analyzed the design considerations for disassembling process, which include the methods, tools, and problems from the perspective of operability, remoteness, and modularization. To accomplish this, we have compared the considerations for each unit process and selected the suitable design conditions for the dry process. In addition to this, the design process was performed by considering remote operation and maintenance using SolidWorks. Main unit devices were manufactured and performance tests were conducted for verification.

3.1. Down-Ender Design Methodology. During the disassembling process, a down-ender is required to move spent fuel (SF) assembly into the hot cell in a vertical position using a crane and subsequently turn the assembly from the vertical to horizontal orientation. For the concept design of the device, SF $16 \times 16$ PWR assembly, minimization of the impact shock during the positioning of the assembly, and modularization for maintenance in a high-radiation environment were considered. The design requirements were derived and $16 \times 16$ PWR SF assembly was analyzed. Additionally, down-ender's shock impact experiment was simulated in SolidWorks using 3D module design. Furthermore, $50 \mathrm{~kg} \mathrm{HM} /$ day throughput and 250 working days per year at full capacity was assumed, and based on Korea 


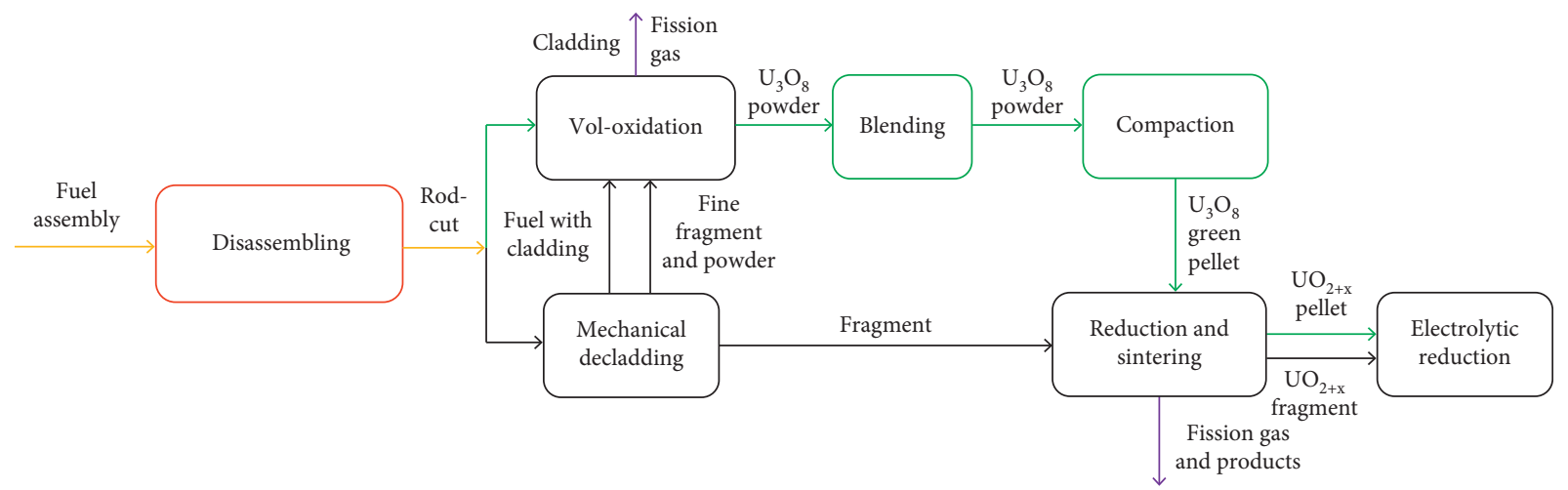

FIGURE 1: Flowchart for the dry head-end process.

TABLE 1: Comparison of the disassembling technology in the head-end processing.

\begin{tabular}{|c|c|c|c|c|}
\hline Country & Purpose & $\begin{array}{c}\text { Dismantling } \\
\text { method }\end{array}$ & Advantage & Disadvantage \\
\hline Korea (KAERI) & $\begin{array}{l}\text { Head-end for } \\
\text { pyroprocessing }\end{array}$ & Wheel cutting & Cutting section good & Small amount processing \\
\hline France (La Hague plant) & $\begin{array}{l}\text { Commercial LWR fuel } \\
\text { reprocessing }\end{array}$ & Mechanical shearing & Mass processing & Shearing section deformation \\
\hline USA (INL EBR-II) & EBR-II spent fuel reprocessing & Punch press & Mass processing & Shearing section deformation \\
\hline Japan (JAEA) & FBR spent fuel reprocessing & Laser & Mass processing & Fuel damage \\
\hline
\end{tabular}

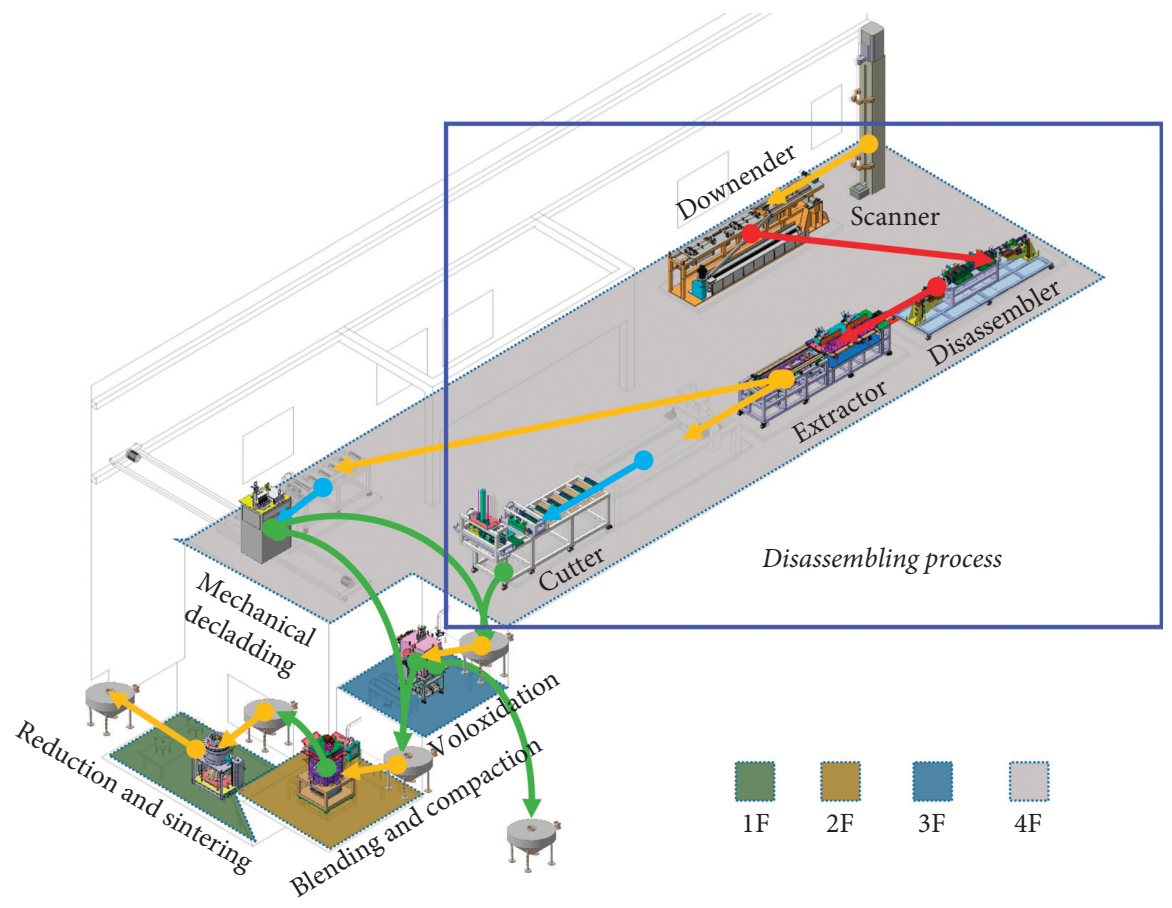

FIgURE 2: Disassembly during dry head-end process.

standard fuel assembly (KSFA) type $(16 \times 16)$, the concept design was conditioned to process 30 Ton HM/year with $85 \%$ availability.

3.2. Dismantling Methodology. The dismantling process design was compared and analyzed based on the characteristics of the SF dismantling methods such as radial single cutting, axial single unbolting and drilling, and axial multidrilling methods for PWR spent fuel assembly. As shown in Figure 4, radial single cutting is a method for cutting the fuel rod in the vertical direction with a single tool. Axial single unbolting and drilling is a method for unbolting and drilling in the axial direction of the fuel rod with a single 


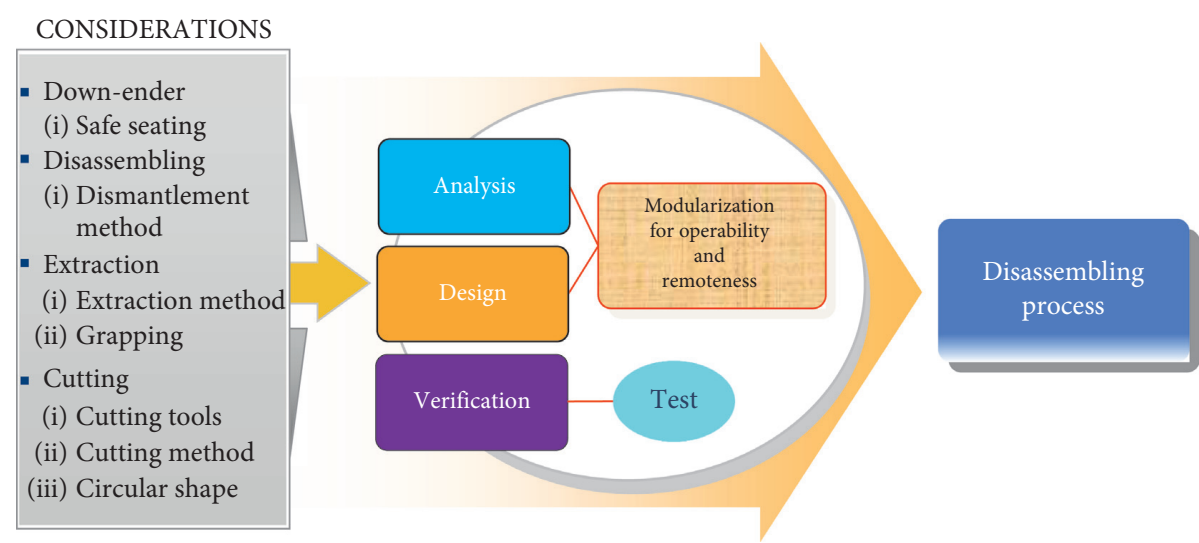

FIgURE 3: Design considerations for disassembling process.

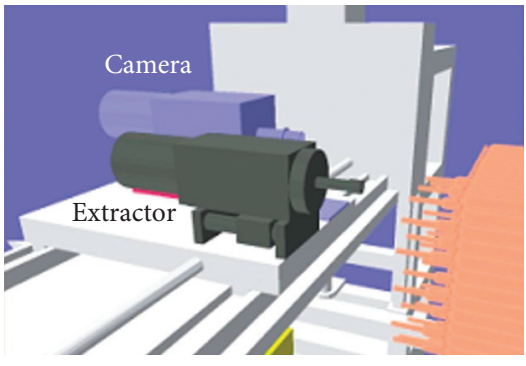

(a)

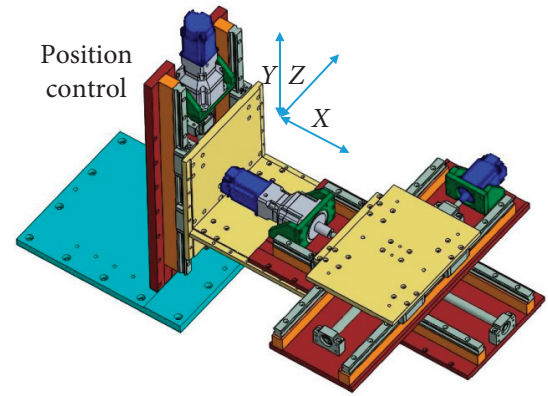

(b)

Figure 4: (a) Vision and (b) data positioning methods for extraction.

tool each, for the top and bottom nozzles. Axial multidrilling is a method for drilling in the axial direction of fuel rod with several tools. We have analyzed the problems that could occur during dismantling of the top and bottom nozzles of the PWR $16 \times 16$ assembly using the three disassembly methods [7]. Requirements of SF disassembler were considered to derive the main mechanism, and concept design was performed using $3 \mathrm{D}$ module analysis.

\subsection{Extraction Methodology. The mechanical extraction} method was compared to position tracking. The vision method, which extracts information by video processing, and position control, which saves the assembly dimension data, were analyzed (Figure 4).

Additionally, the present study analyzed the feasibility of the gripping method for SF extraction to design a highefficiency head-end process [11]. Various extraction methods, such as roller, collet, vertical jaw, and horizontal jaw were analyzed. The requirements of the SF extractor were considered to derive the main mechanism for the extractor and SolidWorks was used to carry out 3D module design for the concept.

3.4. Cutting Methodology. The characteristics of the cutting method in the head-end process is different in the case of the wet method and dry method. In the head-end process, especially, which is a dry process, analysis of the efficient cutting method should be done also considering the mechanical decladding process. Therefore, the present study has analyzed the feasibility of PWR SF rods cutting method, which is a part of the unit process, for the design of a dry disassembling process. The considerations for the use of various tools and cutting methods were analyzed. Moreover, the advantages and the disadvantages of the durability, structure, time required, function, handling, maintenance, radiation resistance, operability, size of the device, power, cutting degree, and required power on the methods such as cutting, shearing, wire cut, grinding, and laser methods were analyzed. For the design of the cutter, modularization was performed for maintenance and failure rates, and the requirements were established in consideration of the analysis results. SolidWorks was used to design the tool in the case as well.

The PWR $16 \times 16$ simulated assembly was fabricated for performance testing in each unit process of the disassembling process [12]. Using the analysis results, the disassembler, extractor, and cutter were modularized and performance tests were conducted for verification. In particular, performance tests of dismantling the upper and lower nozzles in the disassembler, multifuel rods extraction, and multifuel rods cutting were performed. 


\section{Results and Discussion}

\subsection{Down-Ender}

4.1.1. Down-Ender Analysis. For the SF assembly downender concept design, the following requirements were considered. The drive actuator type should be electrically or hydraulically driven if the motors required performance comparison. The speed of the motor speed should be monitored (DC servo is recommended) and the completion of operations should be verified using a proximity switch or alternative sensor. The force applied by the clamping device on the SF assembly should be controlled to prevent bending of space grid, rods, or bottle nozzle, the maximum clamping force applied to each grid should be $240 \mathrm{~kg}_{\mathrm{f}}$, and the maximum clamping force applied to the bottom nozzle shall be within $900 \mathrm{~kg}_{\mathrm{f}}$. To set the open and close position of the clamping device, the internal limit switch should be used. The specifications of the $16 \times 16$ PWR SF assembly are as follows-number of rods $=236$; total length $=452.5 \mathrm{~cm}$; length of each $\operatorname{rod}=409.4 \mathrm{~cm}$; width of each $\operatorname{rod}=20.7 \mathrm{~cm}$; outer diameter of $\operatorname{rods}=0.952 \mathrm{~cm}$, $\operatorname{rod}$ thickness $=0.057 \mathrm{~cm}=$ total mass $=651 \mathrm{~kg}$, uranium mass $=486 \mathrm{~kg}$, and zircaloy mass $=138 \mathrm{~kg}$. The SF downender design was based on the $16 \times 16$ PWR SF assembly.

4.1.2. Down-Ender Design. As shown in Figure 5, the downender comprises of 5 main modules which are motor modules, slide module, clamp module, and the support module. The support module has the main role of providing support when SF assembly is shifted from vertical to horizontal position. The motor module helps the support module to move from vertical to horizontal position. The clamp module provides restraint and support to SF assembly during the process of shifting from vertical to horizontal position.

As shown in Figure 6(a), a concrete structure with a weight of $651 \mathrm{~kg}$ was built to simulate the SF assembly and an acceleration sensor was attached to measure the shock force when the assembly is positioned on the fixing table. When the speed of the rotating motor in the vertical/horizontal portion was set to about $68 \mathrm{~mm} / \mathrm{sec}$, the time taken to shift from vertical to horizontal position was about $28 \mathrm{~s}$. As shown in Figure 6(b), the shock acceleration demonstrates mean and maximum values of approximately $0.1 \mathrm{~g}\left(\mathrm{~g}: 980 \mathrm{~cm} / \mathrm{sec}^{2}\right)$ and $0.3 \mathrm{~g}$, respectively, thereby representing a no-shock scenario during positioning on the fixing table. This was accomplished by stopping the rotating vertical/horizontal part of the simulated assembly before the horizontal position is reached using a proximity switch.

\subsection{Dismantling}

4.2.1. Dismantling Analysis. For the disassembler design, the following major requirements were considered. The maximum clamping forces used for providing support to fuel assembly are $240 \mathrm{~kg}_{\mathrm{f}}$ for each grid and $900 \mathrm{~kg}_{\mathrm{f}}$ for the bottom nozzle. The disassembler should perform the function of cutting and removing the top and bottom nozzle from the guide tube, and it should also have precise position control in 3 axis directions (precision of positioning: $\pm 0.25 \mathrm{~mm}$ ). The cutting tool replacement should be easy, and if possible, it should also provide cooling and lubrication for the cutting tool, collect cuttings, fines, and other waste material for the disposal in the future. It should be designed to avoid the autoignition of $\mathrm{Zr}$ fines generated during the process. To select reasonable and high-efficient targets for PWR SF dismantling methods, the main targets were selected, compared, and analyzed. Radial single cutting, axial single unbolting and drilling, and axial multidrilling methods were analyzed. When the PWR bottom nozzle is cut using the radial single tool, since the gap between the end of the fuel rod and the bottom nozzle is small as shown in Figure 7, the seal welding of the rod pressure port gets damaged and leads to radiation of gas from the rod. Therefore, a visual inspection should be done in advance to check if the rod touches the top nozzle in the hot cell. The top and bottom nozzles of the $16 \times 16$ PWR assembly have 4 bolts and 4 wrenches, respectively, which are removed by 2 tools, therefore dismantling using multiple tools is not necessary. Since this method is simple, the debris produced during the nozzle-removal process is small and overheating can be prevented by continuously supplying nitrogen. In addition, due to the complicated nature of axial multidrilling, maintenance is difficult, a lot of waste is produced while drilling, and nitrogen consumption is high to prevent overheating. As a result of the comparison and the analysis, we have selected the axial single unbolting and drilling method, which can handle the $16 \times 16$ PWR SF assembly, prevents fire during the cutting process, and generate less waste. This method has versatile application as it can be applied to the dry process as well as the wet process.

4.2.2. Disassembler Design. The SF disassembler's main mechanism was designed to carry out identification of the assembly position, automatic positioning on top and bottom nozzles, and unbolting and drilling work whilst identifying the joint location. It also recognizes the location coordinates of $x, y$, and $z$ using the dimensions of the PWR spent fuel assembly that was stored in the data server.

As shown in Figure 8, SF disassembler to remove top and bottom nozzle utilizes the unbolting and drilling module, $X$ $Y$ slide module, clamping module, and support module for PWR dismantling process. SF disassembler includes the drive motor and sensor required for unbolting and drilling module positioning. As shown in Figure 8, this system is composed of five main modules that can be mounted and removed, and the function of each is as follows. The clamping module is an assembly fixing module that fixes the nuclear fuel assembly after being positioned. The unbolting module separates the top nozzle of the fuel assembly by unbolting. In addition to this, the drilling module separates the bottom fixture of the nuclear fuel assembly by drilling. The sliding module moves the unbolting module and drilling module to the working position and the support module is the base platform where all the modules of the main device for disassembly can be fixed. Figure 8 shows the disassembly 


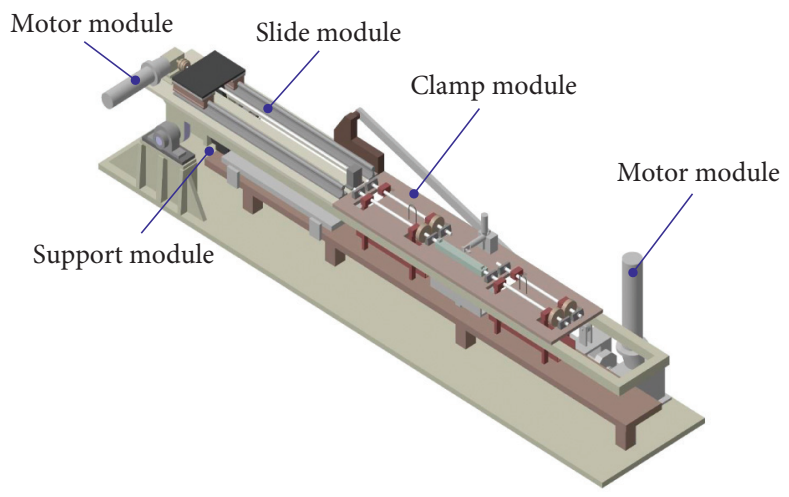

Figure 5: 3D view of SF assembly's down-ender.

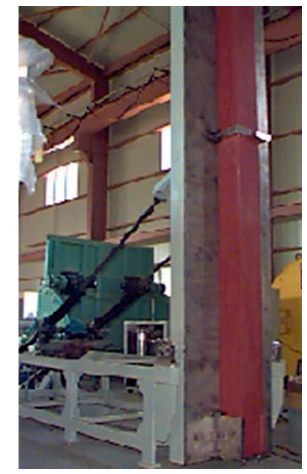

(a)

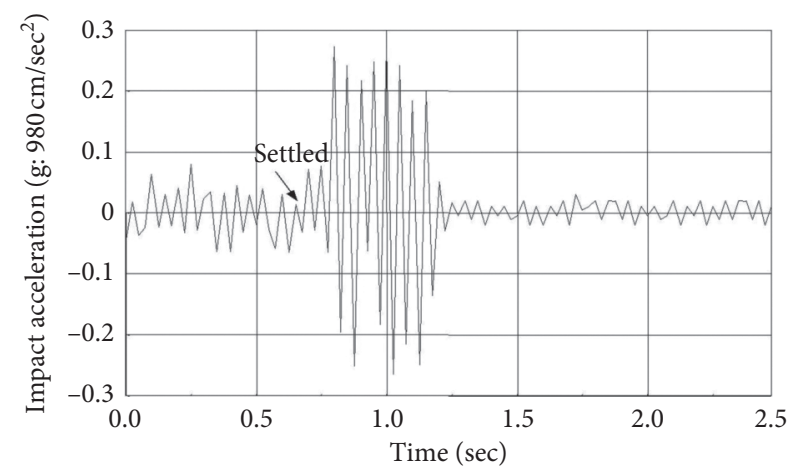

(b)

Figure 6: Impact of assembly on table: (a) test setup and (b) impact acceleration.

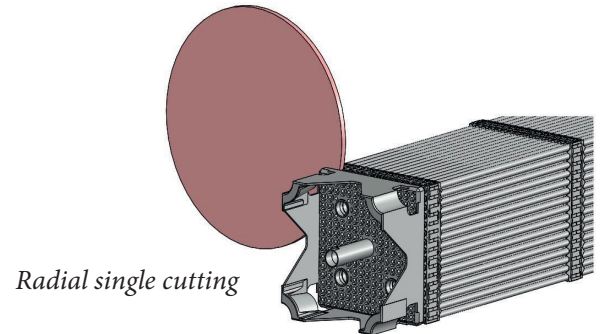

Bottom nozzle

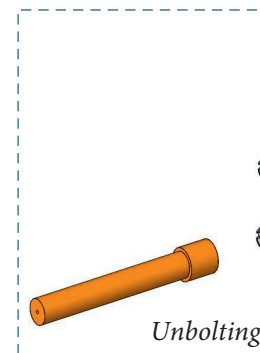

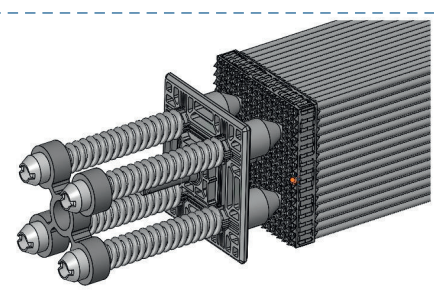

Top nozzle

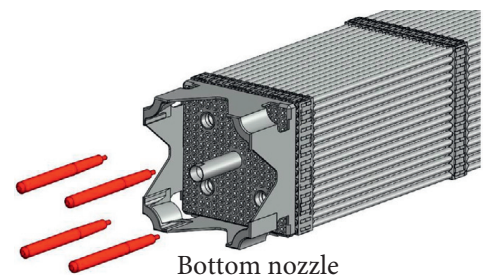

Axial multidrilling

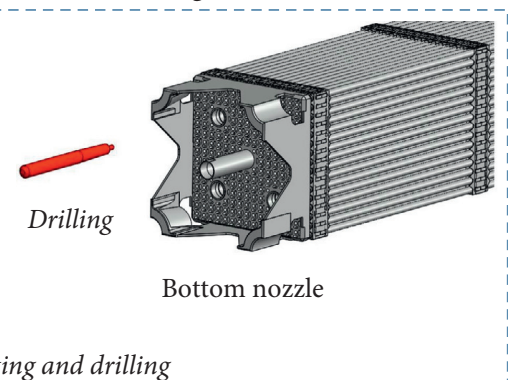

Figure 7: Dismantling methods for $16 \times 16$ PWR assembly. 


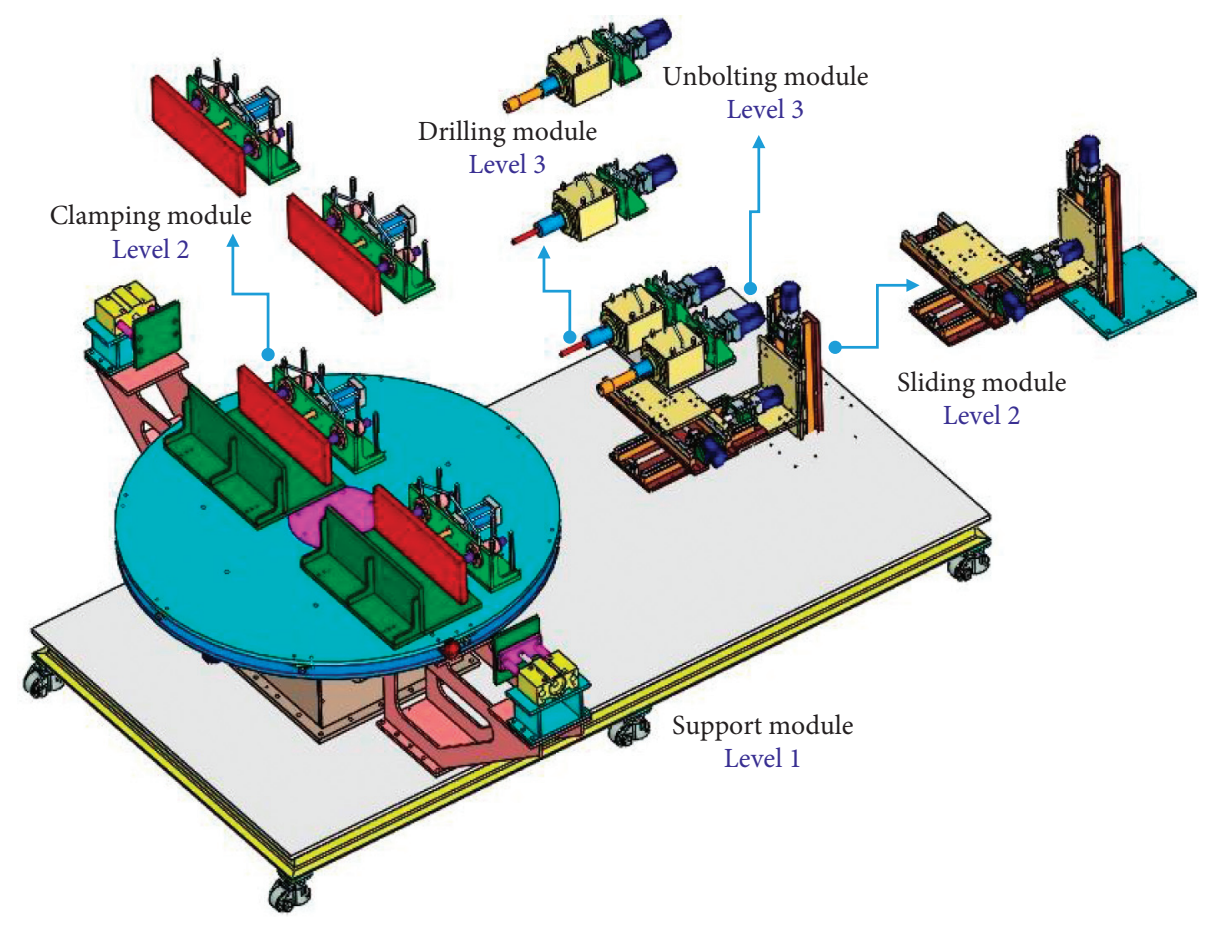

Figure 8: Disassembler modules configuration diagram.

and assembly procedures for the main modules of the disassembler. The module of level 3 can be disassembled or assembled after the sliding module of level 2 is installed, and the modules of level 2 can be disassembled or assembled freely without mutual interference.

\subsection{Extraction}

4.3.1. Analysis of Vision and Positioning Methods. With regard to the technology used to extract the rods from SF assembly, the vision method, which is a video processing technology, and position control extraction method, using the assembly dimension data, are compared. As shown in Table 2, the vision method has comprehensive functions to extract from each assembly type, but the camera and sensor, that provide precise control, are vulnerable to radiation. Due to remote control, the position control method is structurally simpler than the vision method for extraction and has a less failure ratio in radiation environments. Additionally, because of the high-speed positioning, the extraction method is better than the vision method in the rod extraction methods for high throughput extraction.

4.3.2. Analysis of Gripping Methods. In the roller method, the spent fuel rods inside the assembly are extracted from the fuel assembly using the roller in front of the extraction table as shown in Figure 9(a). At present, the contact force of the roller and the rods is controlled by the air cylinder method. In the initial position, the top and the bottom rollers are about 1 inch apart, and when one row of the rods comes closer, the cylinder actuates and the upper roller moves down to touch the rods. When this happens, the rods are held between the two rollers, and when the roller is rotated using an electric motor, the rods come out of the fuel assembly. The rollers have an elastic material that helps in the application of the uniform force on the rods. However, the fuel rods can slip between the rollers, and there is a chance a few fuel rods may not be extracted.

As shown in Figure 9(b), in the collet methods, after removing the top and the bottom nozzle, they are visually checked by a control program to ensure that they are properly removed and handled [13]. The assembly table is rotated by the rod extraction device, and the nuclear fuel assembly is positioned for the removal of the rods. Subsequently, the gripping collet automatically approaches the rods. When the gripper approaches the rods, a proximity sensor detects the closest rod in the nuclear fuel assembly. Then, the gripper lead screw positions the gripper to hold the rod, and the out-of-place rods will be kept as close as possible to the gripper. The collet drive of the gripper holds all the rods of the horizontal row. The gripping tool starts to remove the rods using the extraction collet. However, due to the compactness between the fuel rods, multiple collets cannot be used and they are not suitable for fuel rods extraction for high throughput [14].

In the vertical jaw method, as fuel nipples horizontally enter jig holes of the vertical jaw, 16 fuel rods are clamped at the neck by lowering the vertical jaw pin. The diameter of the neck is smaller than the nipple diameter of the fuel rod as shown in Figure 9(c). After clamping, the fuel rods are extracted by horizontal movement of the vertical jaw module. The vertical jaw method has a simple structure, so remote maintenance and operation are easy [15]. In addition 


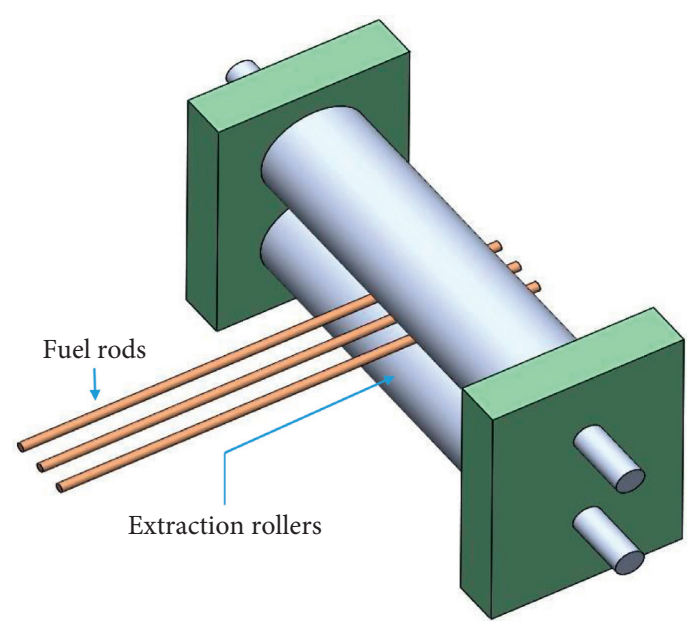

(a)

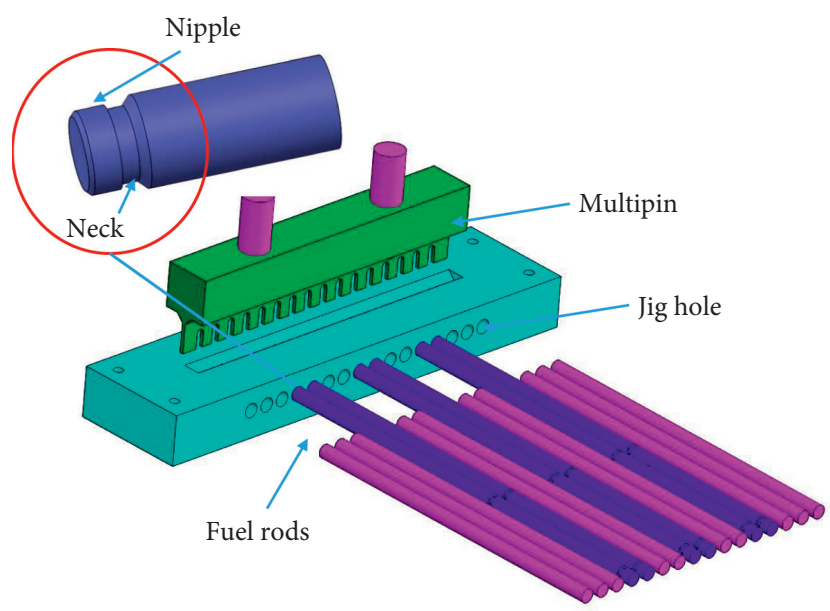

(c)

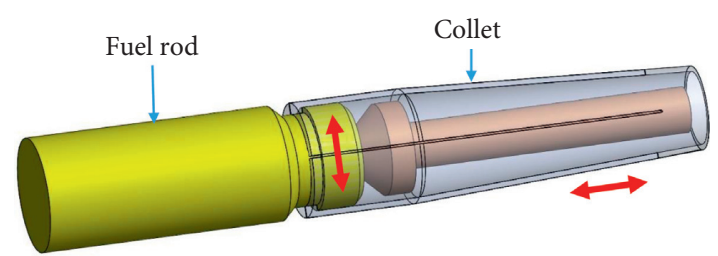

(b)

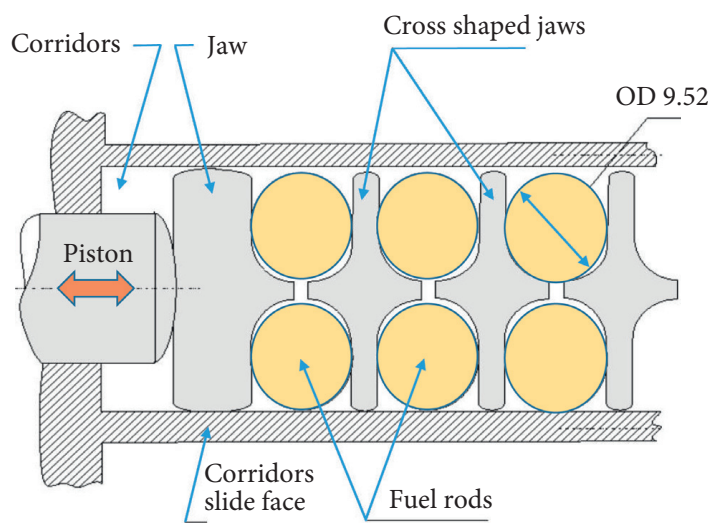

(d)

Figure 9: Gripping methods for rod extraction. (a) Roller. (b) Collet. (c) Vertical jaw. (d) Horizontal jaw.

to this, if the height of the vertical jaw pin and the jig is increased, 32 fuel rods can be simultaneously extracted.

In the horizontal jaw method, when the horizontal gripper reaches the location of the rods, the rods are inserted into the horizontal gripping jaw as shown in Figure 9(d). The force applied to the piston head is transferred to the horizontal gripping jaw in the horizontal direction, and each rod is gripped between the 2 horizontal jaws and the fixed wall. The hydraulic pressure is applied from the edge of the fuel assembly, and when each rod is gripped, the horizontal gripping operation is complete and prepared for rods extraction. When all rods are fixed to the horizontal gripping jaw, it is mounted to the traversing cart. As the cart moves backwards, it pulls the rods. However, due to the complicated machine structure, maintenance is difficult and the failure rate is high.

4.3.3. Extractor Design. For extractor design, the following major requirements were considered. The maximum force with which the gripper can hold the fuel rod is $160 \mathrm{~kg}_{\mathrm{f}}$, and the maximum force to pull the fuel rod from the assembly on the clamping table is $90 \mathrm{~kg}_{\mathrm{f}}$. In addition to this, gripping and extraction forces must be monitored during fuel rod extraction. When the spent fuel assembly is placed on the extraction table, 16 spent fuel rods in the assembly should be extracted at the same time by vertical jaws, and accurate position control in axial and vertical direction should be provided. The gripper of the extractor should be moved to the location of the fuel assembly after identifying that the assembly is placed, and the spent fuel assembly must be firmly clamped. In addition to this, the extractor must be modular in structure for remote operation and maintenance. The modularization design was carried out considering remote operation and maintenance. Figure 10 shows the disassembly and assembly procedures for the main modules of the extractor.

As shown in Figure 10, the main module consists of five submodules, and the function of each is as follows. The clamping module is an assembly fixing module using a cylinder so that the nuclear fuel assembly can be fixed after being placed. The Pusher module pushes the fuel rods by 2 inches out of the assembly to grip the fuel rods. The extraction module extracts the fuel rods of the nuclear fuel 


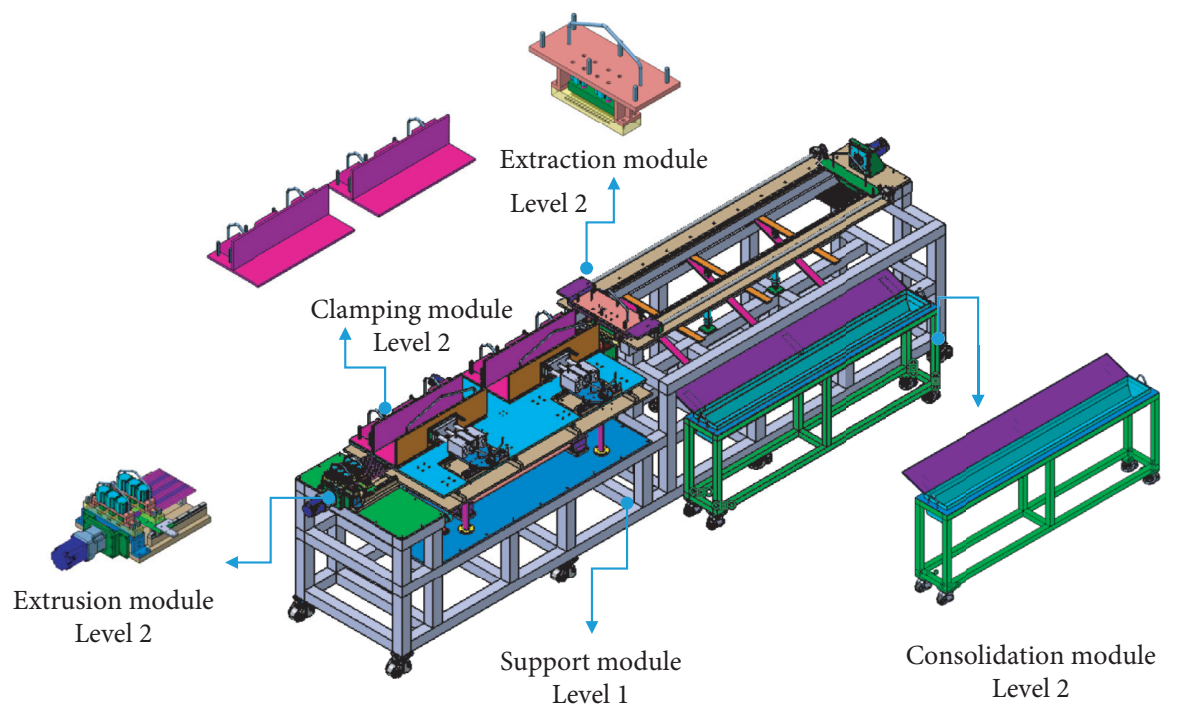

FIgURE 10: Extractor modules configuration diagram.

TABLE 2: Comparison of vision and positioning methods for rod extraction.

\begin{tabular}{|c|c|c|}
\hline Method & Vision method & Positioning method \\
\hline \multirow{8}{*}{ Advantages } & \multirow{4}{*}{$\begin{array}{l}\text { Comprehensive functions to extract various types of assembly } \\
\text { If abnormal rods are observed, location recognition can be easily } \\
\text { compared against other methods }\end{array}$} & A simple structure for extraction \\
\hline & & Low failure ratio \\
\hline & & No need for shielding structure \\
\hline & & Small space is required \\
\hline & Precise control & Easy to design for multiple rod extraction when \\
\hline & Precise contror & compared to vision \\
\hline & Sensors are vulnerable & Difficult to set initial origin position of assembly \\
\hline & Radiation shield structures require more of each element & $\begin{array}{l}\text { New information must be saved according to } \\
\text { assembly type }\end{array}$ \\
\hline Disadvantages & $\begin{array}{l}\text { Device failure ratio is high } \\
\text { A big space is required } \\
\text { Difficult to design for multiple rod extraction }\end{array}$ & Abnormal rods are not easy to handle \\
\hline
\end{tabular}

assembly and moves them to the consolidation module. The consolidation module collects and consolidates the extracted fuel rods before moving them to the cutting device. And the support module is a base platform on which the modules of the main device can be placed. Figure 10 shows the disassembly and assembly procedures for the main modules of the extractor. The modules of level 2 can be disassembled or assembled freely without mutual interference.

\subsection{Cutting}

4.4.1. Cutting Analysis. As shown in Table 3, the advantages and disadvantages of cutting with degree of freedom, shearing in one direction such as punch, wire cutting using wire discharge processing, grinding, and laser cutting were analyzed. The cutting method uses a structure such as disk saw or scissors. The advantages are good final cross section without deformation and precision, and it can be done in any random direction, but a major drawback is that it generates fine particles. Shearing is a method in which a structure such as a punch or die is used for the cutting of SF assembly and rods. The advantage of this method is that there is no generation of fine particles that are hard to remove from the shearer. But it has the disadvantage that the sheared cross section is rough and blunt, while the operation is quick and the productivity is high. Wire method (wire electrodischarge machining (EDM)) is the method of cutting with a brass electrode passing through metal, and electrons are released. Grinding is used widely for SF rods cutting in air or water, inside the hot cell. Cutting in water minimizes the spread of the dust and prevents the flare generation from the fine particle of zircaloy during the cutting. Design was made for easy replacement of the cutting wheel, collection of zircaloy powders from a large amount of ultrafine particles ( $1 \mu \mathrm{m}$ or less) produced, and the prevention of the powder accumulation around the equipment. Laser cutting method is developed to remove the structure, such as top and bottom nozzles of the SF rod assembly, and it can cut without generating dust [16]. The equipment that requires maintenance is installed outside the hot cell, and the gripping mechanism and laser cutter are installed inside the hot cell. 
TABLE 3: Analysis of cutting methods according to various criteria (merits: M, faults: F).

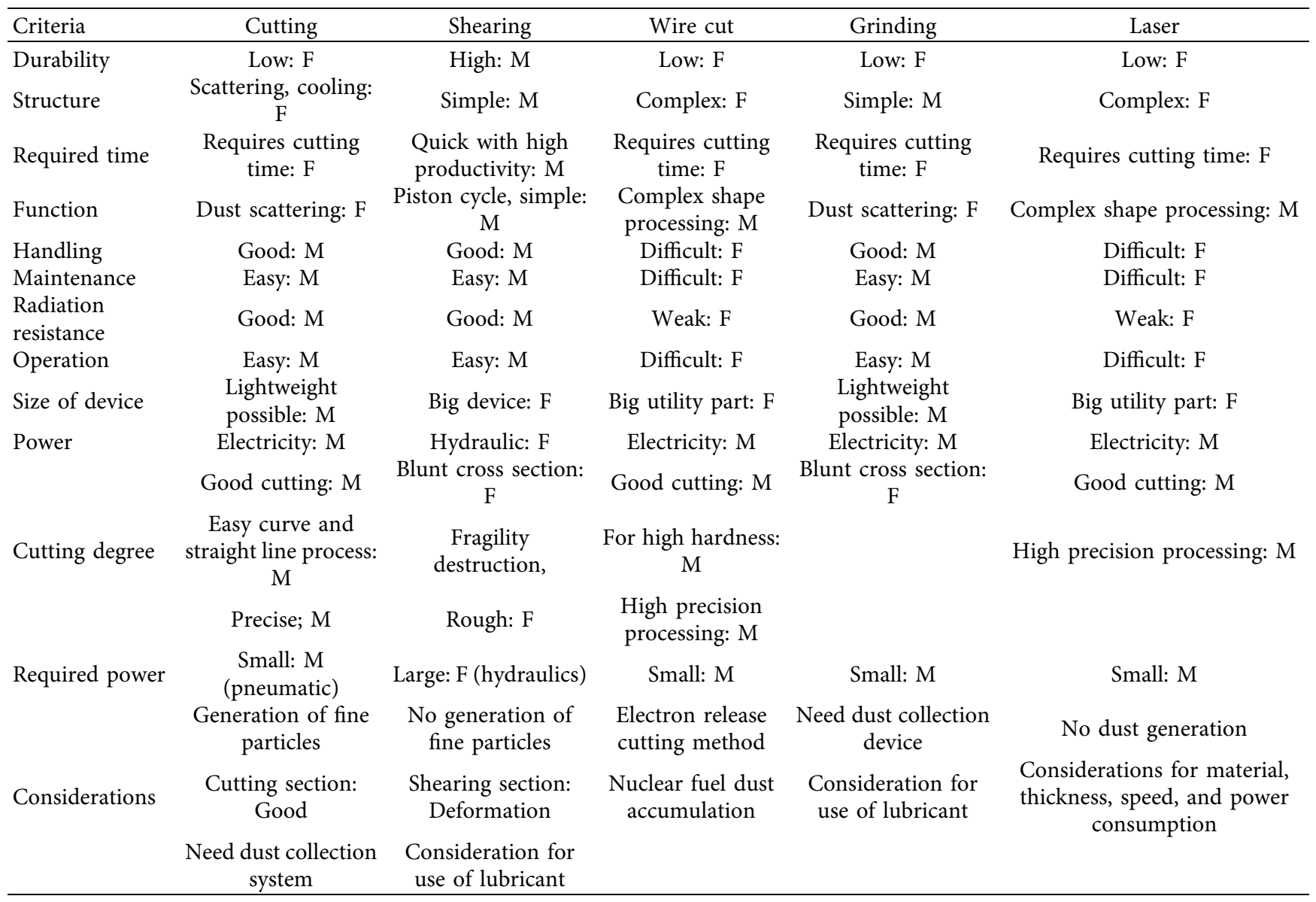



FIGURE 11: Cutter modules configuration diagram. 

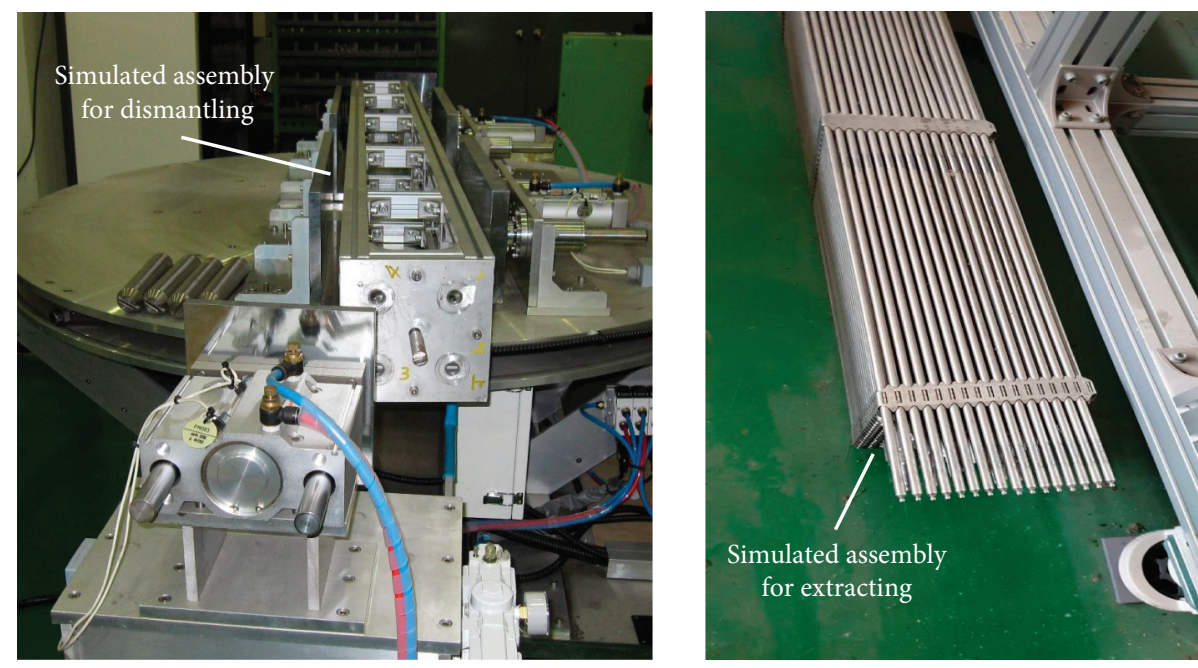

(a)

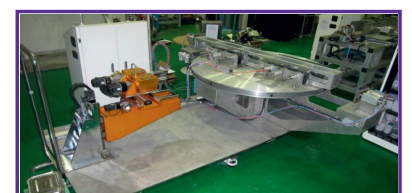

Disassembler

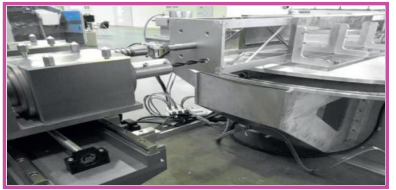

Drilling

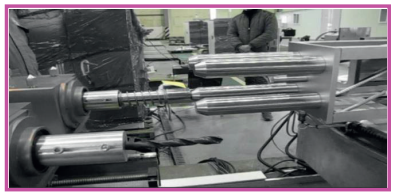

Unbolting

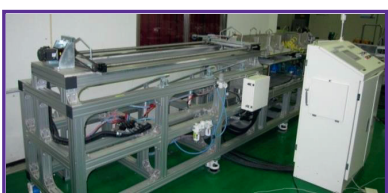

Extractor

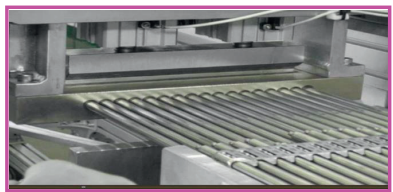

Extracting

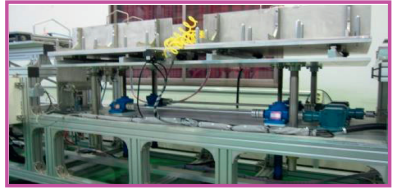

Position control

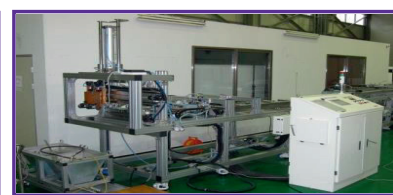

Cutter

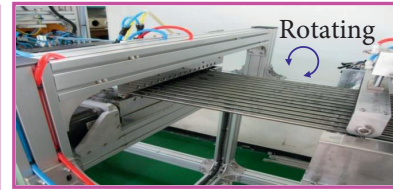

Rotating and transfer

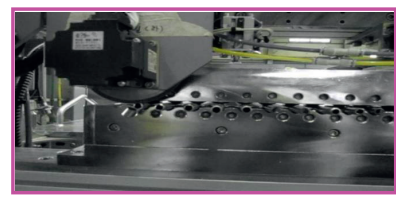

Cutting

(b)

FIGURE 12: Disassembling unit process test. (a) simulated assemblies. (b) Dismantling, extracting, and cutting tests.

The disadvantages are that minute control of the cutting depth is not possible and the price of the equipment is high [16].

The rod-cut (tube + pellets) supplied to the mechanical decladding process should not be deformed. In addition, the power of the radiation zone is more suitable for pneumatic power than hydraulic power as hydraulic oil gets degraded. Therefore, the cutting method is more advantageous than the shearing and wire cut method.

4.4.2. Cutter Design. For the design of fuel rods cutter, the following main requirements were considered. The fuel rodcut section should not be deformed for subsequent processing, and the horizontally mounted fuel rods must be cut at regular intervals. The cutter should have the provision for aligning with the fuel rod, and the feeder and transport clamp should be designed to transfer the fuel rods to the cutting area. In addition to this, it should be designed with a modular structure that is easy to maintain during operation. The operation configuration should be as follows. When the placed fuel rod is transferred to the cutting region by the roller, a notch is made around the cut fuel rods up to a certain depth using a CBN (Cubic Boron Nitride) wheel disc. The cut fuel rods having a length of $500 \mathrm{~mm}$ are dropped into the collection container by the impact from the compression ram [17].

As shown in Figure 11, the main module consists of 6 submodules, and function of each is as follows. The cutting module is a device that cuts the fuel rods to the appropriate depth for notching. The impacting module is a device that impacts the fuel rods and moves them to the collection module. The transfer module is a device that moves the fuel rods to the cutting module when the aligned fuel rods enter the clamp module. The clamping module is a device to clamp the fuel rods before moving them to the cutting module. The collection module is a container where the rod-cuts are collected, and the support module is a base platform on 
which the modules of the main device can be placed. Figure 11 shows the disassembly and assembly procedures for the main modules of the cutter. The module of level 3 can be disassembled or assembled after the cutting module of level 2 is installed, and the modules of level 2 can be disassembled or assembled freely without mutual interference.

4.5. Disassembling Test. As shown in Figure 12(a), a simulated nuclear fuel assembly was fabricated for dismantling, extraction, and testing. The simulated nuclear fuel assembly was designed to be $50 \%$ of the actual assembly length, and the extracted fuel rods were used for the cutting test. As shown in Figure 12(b), the main processes of SF dismantling device, including position identification of the unbolting/ drilling module and automatic positioning on top and bottom nozzles fittings, have been simulated. During the preliminary performance test, four bolts of the top nozzle of the simulated assembly were dismantled properly by unbolting, and the four wrenches of the bottom nozzle were dismantled by drilling. As shown in Figure 12(b), the main mechanism of the extractor has been replicated and it simultaneously extracts the fuel rods using the extraction module, located in front of the assembly, after the assembly is fixed on the extraction table. In the preliminary performance test, the lifting system accurately placed the assembly on the extraction module through $y$ and $z$ control, and the extraction module simultaneously extracted 16 fuel rods from the assembly. As shown in Figure 12(b), the cutting device was manufactured, and its function was to control the rotation and feed rate of the cutting blades using the submotor and cut 16 extracted fuel rods at the same time. In the preliminary performance test, the fuel rods were transferred by the fuel rod transfer module. The CBN wheel was accurately controlled by a servo motor, and 16 fuel rods were simultaneously cut using fuel rod-cutting and impacting tools.

\section{Conclusions}

Dry disassembling process of down-ender, dismantling, extraction, and cutting should be performed at the beginning of the head-end pyroprocessing. Drilling and unbolting, fuel rod extraction, and $\mathrm{CBN}$ wheel cutting methods were adopted as main procedures for each unit process of the disassembly using the analysis results. Additionally, 3D modularization was performed by selecting remote objects and using SolidWorks for each device. During down-ender design, for an angular speed of $3 \mathrm{rad} / \mathrm{sec}$ in moving from the vertical to horizontal orientation, mean and maximum angular acceleration values of about $0.1 \mathrm{~g}$ and $0.3 \mathrm{~g}$, respectively, were observed, thereby representing a no-shock condition. Per design requirements, the horizontal clamp force applied to grid equaled $240 \mathrm{~kg}_{\mathrm{f}}$, vertical clamp force applied to bottom nozzle is within $900 \mathrm{~kg}_{\mathrm{f}}$, and the turning time from the vertical to horizontal position was set as $30 \mathrm{sec} / 90^{\circ}$. For rational removal of top and bottom nozzles, appropriate nozzle-removal methods have been proposed, compared, and analyzed. We selected the axial single unbolting and drilling method, which can handle the $16 \times 16$ PWR SF assembly, prevent fire during the cutting, and generate less waste. Additionally, this method has versatile applications as it can be used for the dry process as well as wet process. For the feasibility analysis of PWR spent fuel assembly rods extraction method, the vision and the positioning extraction methods were analyzed, and the gripping methods that use roller, collet, vertical jaw, and horizontal jaw were analyzed. The positioning extraction method was better than the vision method from the point of failure occurrence and high throughput, and the vertical jaw gripping method, which can handle $16 \times 16$ PWR SF assembly rods and can extract many nuclear fuel rods at the same time, were selected. In order to select the cutting method, the considerations were made based on the use of various tools. Moreover, the advantages and the disadvantages of the criteria, such as the durability, structure, and maintenance, were analyzed. The cutting method was found to be more advantageous than the shearing, wire cut, grinding, and laser methods for the dry disassembling process. The modular designs were developed in SolidWorks for remote operation and maintenance in the head-end unit processes in a radiation environment. In the verification test, the four bolts of the top nozzle in the simulated assembly were dismantled perfectly by unbolting, and the four wrenches of the bottom nozzle were dismantled by drilling. The extraction module simultaneously extracted 16 fuel rods from the assembly, and the 16 extracted fuel rods were simultaneously cut using fuel rod-cutting and impacting tools.

However, the ability to collect the cuttings, fines, and other waste material for future disposal should be provided. Additionally, in order to develop a practical-scale dry disassembling process, connectivity, and remoteness between unit processes should be studied.

The design considerations for the disassembling process can help in the optimum design of a dry head-end process with high throughput, and it can be utilized in the design of a more efficient disassembling process in the near future.

\section{Data Availability}

The data supporting the findings of this study can be availed from the corresponding author upon request.

\section{Conflicts of Interest}

The authors declare no conflicts of interest regarding the publication of this paper.

\section{Acknowledgments}

This work was supported by the National Research Foundation of Korea (NRF) through a grant funded by the Korea government (MEST) (no. 2012M2A8A5025696).

\section{References}

[1] K.-C. Song, H.-S. Lee, J.-M. Hur, J.-G. Kim, D.-H. Ahn, and Y.-Z. Cho, "Status of pyroprocessing technology development 
in Korea," Nuclear Engineering and Technology, vol. 42, no. 2, pp. 131-144, 2010.

[2] H. Lee, G.-I. Park, J.-W. Lee et al., "Current status of pyroprocessing development at KAERI," Science and Technology of Nuclear Installations, vol. 2013, Article ID 343492, 11 pages, 2013.

[3] H.-S. Lee, G.-I. Park, K.-H. Kang et al., "Pyroprocessing technology development at kaeri," Nuclear Engineering and Technology, vol. 43, no. 4, pp. 317-328, 2011.

[4] Y. H. Kim, Y. Z. Cho, Y. S. Lee, and J. M. Hur, "Engineering design of a mechanical decladder for spent nuclear rod-cuts," Science and Technology of Nuclear Installations, vol. 2019, Article ID 9273503, 16 pages, 2019.

[5] G. D. Del Cul, B. B. Spencer, R. D. Hunt, and E. D. Collins, "Advanced head-end processing of spent fuel," in Proceedings of the 2005 ANS Annual Meeting, San Diego, CA, USA, June 2005.

[6] N. Tomohiro and Y. Sakamura, "Conceptual design study of pyro-reprocessing facilities for LWR MOX fuel using electroreduction and electrorefining techniques," in Proceedings of the GLOBAL 2005, Tsukuba, Japan, October 2005.

[7] Y. Tooya, T. Washiya, K. Koizumi, and S. Morita, "Design study of mechanical disassembly system for FBR fuel reprocessing," in Proceedings of the 14th International Conference on Nuclear Engineering ICONE14-89374, pp. 907-912, Miami, FL, USA, July 2006.

[8] M. F. Simpson, "Projected salt waste production from a commercial pyro-processing facility," Science and Technology of Nuclear Installations, vol. 2013, Article ID 945858, 8 pages, 2013.

[9] Y. H. Kim, Y. Z. Cho, J. W. Lee, J. H. Lee, S. C. Jeon, and D. H. Ahn, "Engineering design of a Voloxidizer with a double reactor for the hull separation of spent nuclear fuel rods," Science and Technology of Nuclear Installations, vol. 2017, Article ID 9854830, 12 pages, 2017.

[10] J.-M. Shin and J.-J. Park, "Trapping characteristics of cesium in off-gas stream using fly ash filter," Korean Journal of Chemical Engineering, vol. 18, no. 6, pp. 1010-1014, 2001.

[11] S. H. Ahn, J. H. Jin, and J. S. Yoon, "Development of a teleoperated manipulator system for remote handling of spent fuel bundles," KNS, vol. 35, pp. 214-225, 2003.

[12] R. S. Daum, S. Majumdar, H. Tsai et al., "Mechanical property testing of irradiated Zircaloy cladding under reactor transient conditions," in Small Specimen Test Techniques, vol. 4, pp. 195-210, American Society for Testing Materials, West Conshohocken, PA, USA, 2002.

[13] S.-H. Hong, J. W. Jeon, T. G. Song, J. Y. Lee, S. H. Kim, and J. S. Yoon, "A real-time graphic simulator to monitor spent nuclear fuel dismantlement devices," Nuclear Technology, vol. 139, no. 3, pp. 263-273, 2002.

[14] M. W. Cho and J. S. Yoon, "Multi-functional head for spent fuel nuclear fuel rod extraction," United States patent, patent number: 6,459,749 B1, 2002.

[15] F. J. Formanek, "Tool for pulling multiple rods from A nuclear fuel assembly," United States patent, patent number: 4,687,245, 1987.

[16] G. L. Goswami, A. Chatterjee, and M. Chandra, "Development of automatic remotely operable laser cutting system for disassembly of PHWR spent fuel," BARC Newsletter, vol. 249, pp. 116-122, 2004.

[17] T. Washiya, J. Komaki, and H. Funasaka, "Development of advanced head-end systems in "NEXT" process," in Proceedings of the GLOBAL 2007, Boise, Idaho, September 2007. 